\title{
The relation between food intake and abomasal emptying and small intestinal transit time in sheep
}

\author{
By P. C. GREGORY, S. J. MILLER AND A. C. BREWER \\ Rowett Research Institute, Bucksburn, Aberdeen AB2 9SB
}

(Received 2 August 1984 - Accepted 26 October 1984)

\begin{abstract}
1. The relation between the level of food intake and gastrointestinal motility and digesta flow in the abomasum and small intestine was studied in sheep fitted with nichrome-wire electrodes in the gut wall, an abomasal and a duodenal catheter and a terminal ileal cannula.

2. Abomasal volume and outflow were calculated from CrEDTA dilution in six sheep and small intestinal transit time by the passage of Phenol Red in ten sheep.

3. The frequency of the migrating myoelectric complex of the small intestine was not altered by the level of food intake but the duration of the periods of irregular spiking activity, the amplitude of abomasal activity and the frequency of duodenal rushes were decreased as the level of food intake was decreased.

4. There was a linear relation between the level of food intake (FI) and abomasal outflow (mean with SEM: $327(69) \mathrm{ml} / \mathrm{h}$ for each $\mathrm{kg} \mathrm{FI} / \mathrm{d} ; P<0.01$ ), and abomasal volume (mean with SEM: $344(50) \mathrm{ml} / \mathrm{kg} \mathrm{FI} \mathrm{per} \mathrm{d;}$ $P<0 \cdot 001$ ), without any significant change in the half-time of marker dilution in the abomasum. Small intestinal transit time decreased with an increase in food intake (mean with SEM: $-54.9(5.6) \mathrm{min} / \mathrm{kg}$ Fl per d; $P<0.001$ ).

5. It is concluded that abomasal volume and the rate of digesta flow from the abomasum and along the small intestine are linearly related to the level of food intake.
\end{abstract}

The digestibility of a diet is partly dependent on the rate of passage of digesta through the various compartments of the gastrointestinal (GI) tract, and one of the major factors influencing this in sheep is the level of food intake. While many studies have emphasized the decrease in overall mean retention time of a marker with an increase in the level of food intake (Demarquilly \& Journet, 1967; Leaver et al. 1969; Alwash \& Thomas, 1971; Grovum \& Williams, 1973a, 1977), only a few direct measurements of compartmental changes in volume or digesta passage have been made; these concerned retention times in the reticulo-rumen (Grovum \& Williams, 1977) and the small and large intestine (Coombe \& Kay, 1965). Changes in abomasal volume and flow especially, and of transit through the small intestine over a wide range of food intakes, remain to be established.

The rate of flow of digesta through the small intestine (Bueno et al. 1975) and abomasal emptying (Ruckebusch \& Bueno, 1977) vary according to the phase of the intestinal migrating myoelectric complex (MMC). In the present study, changes in abomasal volume and emptying and of small intestinal transit time have been measured during the period of irregular spiking activity (ISA) of the duodenum over a range of food intakes.

The experiments represent the first stage of a study of the effects of a parasitic infection on gut motility (Gregory \& Wenham, 1984). It was expected that the parasites would cause some inappetence. To be able to assess separately the effects of parasitization and of reduced food intake on gut motility and digesta flow, it was necessary to establish, before infestation of the sheep, the relations between food intake and digesta passage. Since these relations have not been described previously, they are reported separately from the findings on parasitization (Gregory \& Wenham, 1984). The results indicate that there is a close relation between the level of intake and the time which digesta spends in the abomasum and small intestine. 


\section{METHODS}

\section{Animals}

Ten female Suffolk-Finn Dorset cross sheep were used. They had been raised parasite-free to 4-6 months of age in order to carry out the experiments reported by Gregory \& Wenham (1984). Up to twelve sets of three nichrome-wire electrodes were sewn into the musculature of the GI tract, in the reticulum, abomasum, duodenal bulb, descending duodenum, proximal jejunum, 2, 4 and $8 \mathrm{~m}$ distal to the jejunal electrode, and the terminal ileum, as previously described for the forestomach (Gregory, 1982). At the same time a duodenal catheter (polyvinyl chloride, $2 \mathrm{~mm}$ diameter) was implanted $60-80 \mathrm{~mm}$ from the pylorus, and a simple Perspex T-cannula (barrel diameter $15 \mathrm{~mm}$ ) was placed in the terminal ileum about $300 \mathrm{~mm}$ from the ileo-caecal junction. In six of the animals an abomasal catheter (polyvinyl chloride, $8 \mathrm{~mm}$ diameter) was also fitted. All surgery was performed with aseptic precautions under Halothane anaesthesia. The animals were allowed at least 2 weeks to recover from surgery before experimentation and were housed in metabolism cages under continuous lighting.

\section{Experimental design}

The animals were fed on diet AA6, a pelleted complete ruminant diet containing $300 \mathrm{~g}$ barley straw/kg (Wainman et al. 1975). To minimize the variability in digesta flow caused by feeding, the animals were kept as near as possible to continuous feeding conditions by providing a slow continuous supply of food by a belt-feeder. The supply of food was initially regulated such that there was a small refusal per $\mathrm{d}$ to establish the voluntary intake (ad lib. feeding). Intakes were then restricted in random order to about $25,40,55,70$ and $85 \%$ of the voluntary intake for $5 \mathrm{~d}$. Measurements were made on days 4 and 5 and the animals were then returned to $a d$ lib. feeding for $5 \mathrm{~d}$ between each food restriction. Water was freely available at all times. The body-weights of the animals remained fairly steady, changing only from (mean with SEM) $32.9(1.4)$ to $34.9(1.3) \mathrm{kg}$ during the course of the study (2 months).

\section{Measurement of motility and digesta flow}

GI motility was recorded continuously from the implanted electrodes via a twelve channel Polygraph (Grass Model 7D) for periods of 1-3 d. The transit time of digesta passage along the small intestine was measured by rapid injection of $5 \mathrm{ml}$ Phenol Red solution $(20 \mathrm{~g} / \mathrm{l})$ into the duodenal catheter during the ISA, i.e. soon after the resumption of duodenal rushes following a period of regular spiking activity (RSA) in the duodenum (Grivel \& Ruckebusch, 1972), and sampling for the peak appearance of the marker in the digesta at the terminal ileal cannula (Barreiro et al. 1968).

Abomasal outflow and volume were estimated by dilution of CrEDTA, which has been shown to be a suitable marker for abomasal as well as ruminal flow (Hogan, 1964). The CrEDTA was prepared by a modification of the method of Downes \& McDonald (1964) using a solution containing $100 \mathrm{~g} \mathrm{CrCl}_{3} \cdot 6 \mathrm{H}_{2} \mathrm{O}$ and $124 \mathrm{~g}$ disodium EDTA/l and omitting radioactive Cr. A $30 \mathrm{ml}$ dose of this CrEDTA was injected directly into the abomasum at a time when duodenal activity had resumed following a duodenal RSA. Samples of abomasal contents, $20 \mathrm{ml}$, were withdrawn at intervals via the abomasal catheter until the $\mathrm{Cr}$ had disappeared. The samples were centrifuged at $1560 \mathrm{~g}$ for $20 \mathrm{~min}$, and the supernatant fraction acidified with hydrochloric acid and analysed for $\mathrm{Cr}$ at $357.9 \mathrm{~nm}$ in an atomic absorption spectrophotometer (Binnerts et al. 1968). The abomasal volume was estimated from $\mathrm{Cr}$ concentration extrapolated to time of dosing. The half-time $(t / 2)$ of the 


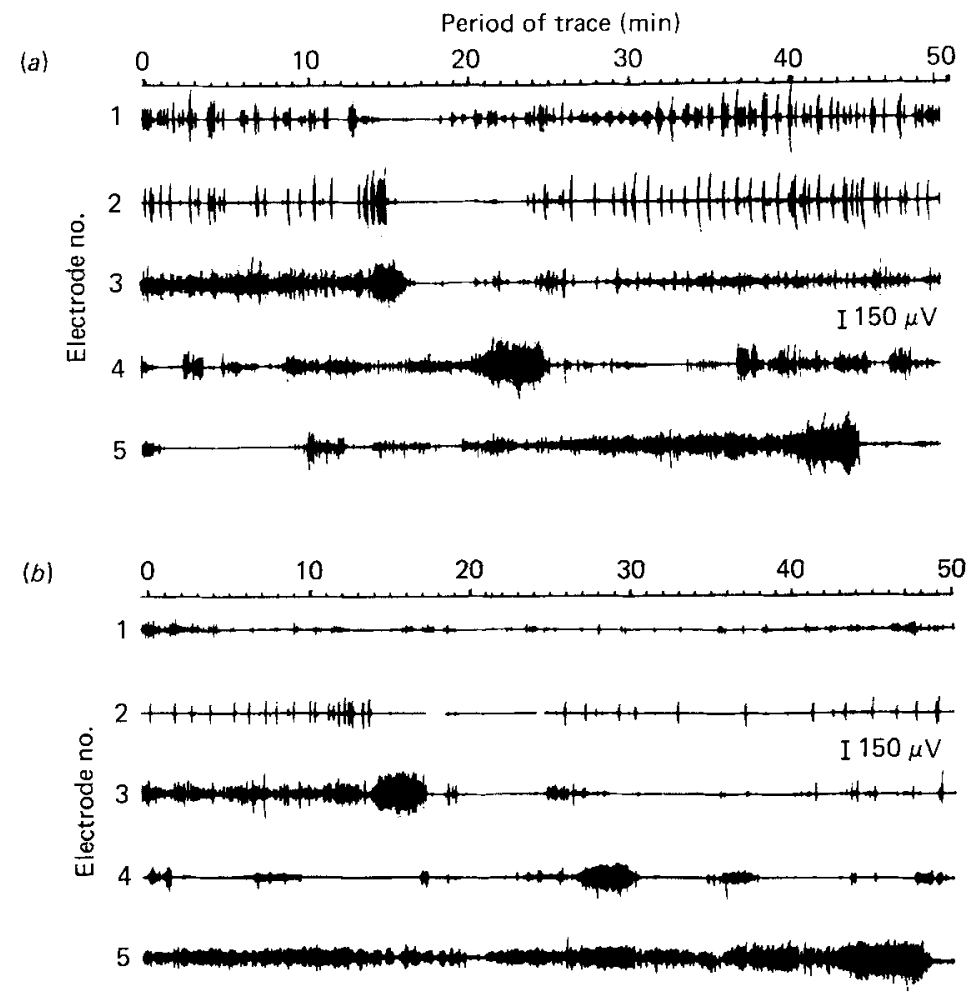

Fig. 1. The influence of the level of food intake on abomasal and small intestinal motility recorded by electromyography. (a) Recording from sheep no. 5760 with a food intake of $1679 \mathrm{~g} / \mathrm{d}$. (b) Recording from sheep no. 5760 with a food intake of $500 \mathrm{~g} / \mathrm{d}$. Electrode 1, abomasal antrum $100 \mathrm{~mm}$ from pylorus; electrode 2 , duodenal bulb; electrode 3 , descending duodenum; electrode 4 , proximal jejunum; electrode $5,4 \mathrm{~m}$ distal to electrode no. 4 .

marker in the abomasum was measured directly from the graph of log concentration of $\mathrm{Cr} v$. time, and the abomasal outflow was calculated from the formula:

$$
\text { flow }=\frac{\text { volume } \times 0.693}{t / 2},
$$

described for the rumen by Warner \& Stacy (1968).

The relations between abomasal volume, $t / 2$ and flow, and also of small intestinal transit time $v$. level of food intake, were subjected to linear regression analysis for the individual animals. The mean regressions were then tested for significance by Student's $t$ test.

\section{RESULTS}

\section{Effect of food intake on GI motility}

The frequency of the MMC was unaffected by the level of food intake. At voluntary intake (mean intake with SEM: 1047 (75) g/d) there were 18 (2) duodenal and 23 (3) jejunal MMC per $24 \mathrm{~h}$, and with food intake restricted to $30 \%$ of the voluntary level there were 18 (2) duodenal and 21 (3) jejunal MMC per $24 \mathrm{~h}$. However, changes were seen in the pattern of the MMC. The frequency of duodenal rushes and the period of ISA decreased and the length 


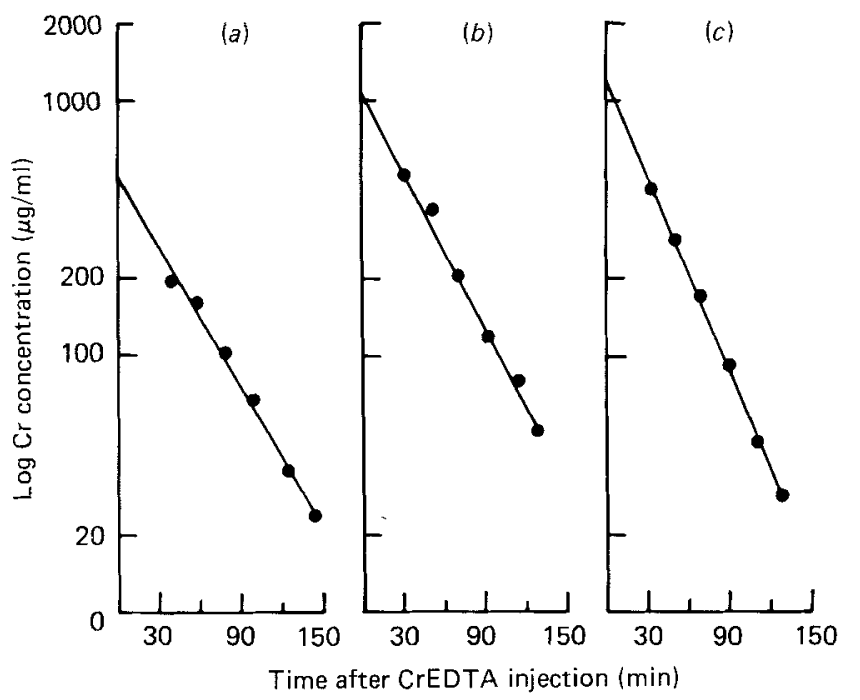

Fig. 2. The measurement of abomasal volume and outflow by dilution of CrEDTA. The graphs show the dilution of a single injection of CrEDTA at three levels of food intake in one sheep (no. 5760). (a) Food intake (FI) $1744 \mathrm{~g} / \mathrm{d}$, half-time ( $t / 2$ ) of marker dilution $33 \mathrm{~min}$, abomasal volume (V) $871 \mathrm{ml}$, flow (F) $1097 \mathrm{ml} / \mathrm{h}$. (b) FI $1293 \mathrm{~g} / \mathrm{d}, t / 230 \mathrm{~min}, \mathrm{~V} 624 \mathrm{ml}, \mathrm{F} 865 \mathrm{ml} / \mathrm{h}$. (c) FI $600 \mathrm{~g} / \mathrm{d}, t / 224 \mathrm{~min}, \mathrm{~V}$ $462 \mathrm{ml}, \mathrm{F} 800 \mathrm{ml} / \mathrm{h}$.
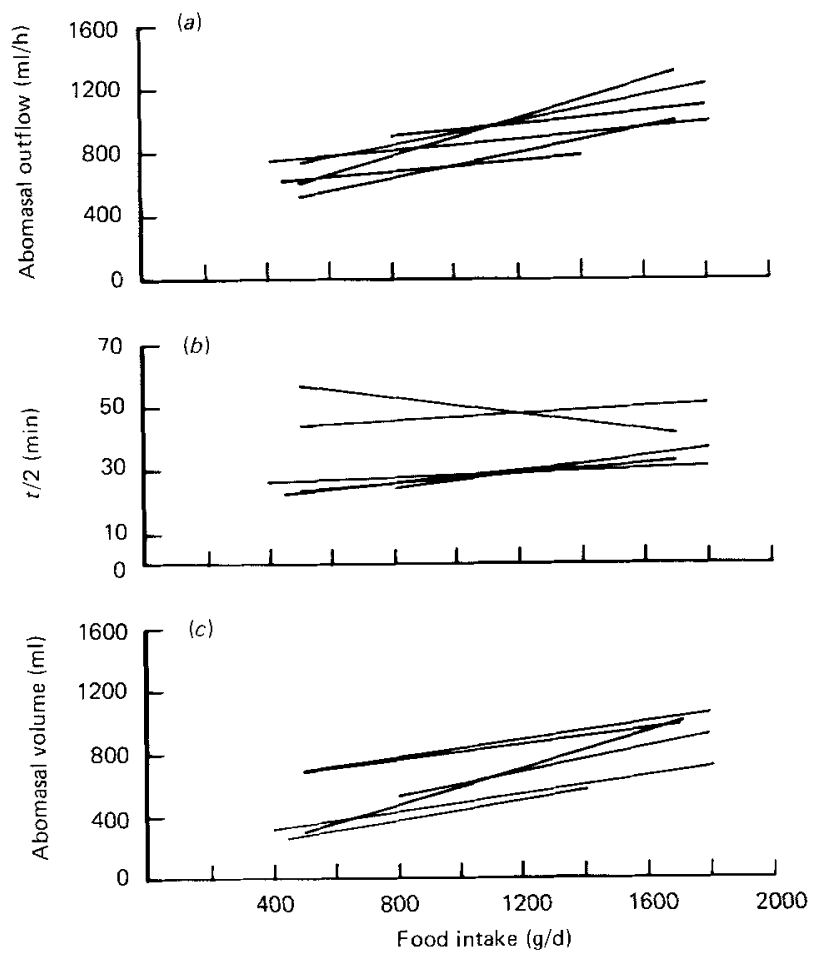

Fig. 3. The individual regressions of six sheep showing the effect of the level of food intake on: (a), abomasal outflow; $(b)$, half-time $(t / 2)$ of marker dilution; $(c)$, abomasal volume, from values estimated by dilution of a single injection of CrEDTA. 


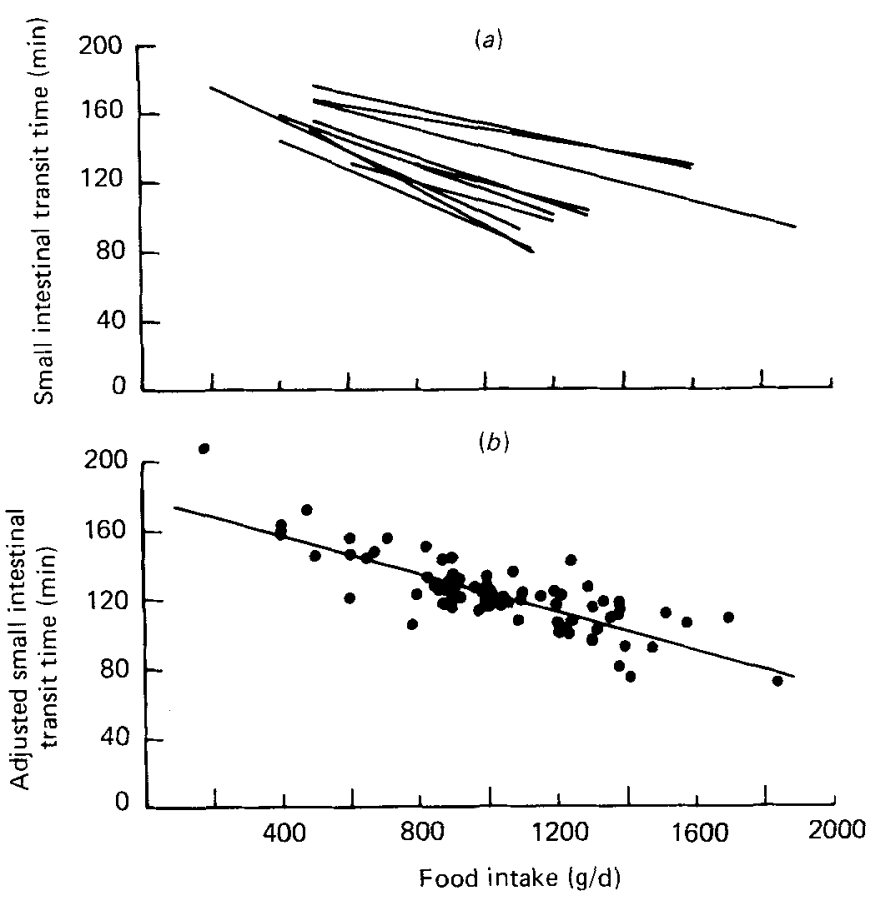

Fig. 4. The influence of the level of food intake on the rate of transit from the duodenum to the terminal ileum measured by passage of Phenol Red marker. $(a)$ The individual regressions of ten sheep. $(b)$ The result of parallel line regression analysis. The line shown is the common within-animal regression ( $r$ 0.739) with a slope of -0.0549 (SE 0.0057 ) and it has an intercept equal to the mean of the individual intercepts from each animal. The plotted points $(n 73)$ are of the transit times from each animal adjusted according to the differences between the animals' intercept and the mean intercept.

of the quiescent period increased with decrease in food intake (Fig. 1) while the amplitude of abomasal spiking activity was reduced at the lowest levels of food intake.

\section{Effect of food intake on abomasal volume and outflow}

A straight-line relation of the $\log$ concentration of $\mathrm{Cr} v$. time was generally observed in all animals and at all levels of food intake as illustrated in Fig. 2. In fourteen of a total of eighty-eight measurements a straight line was not observed, and these results were discarded.

A linear relation was observed in each animal between the level of food intake and abomasal outflow (Fig. 3a), $t / 2$ (Fig. $3 b$ ) and abomasal volume (Fig. $3 c$ ). For each of these the individual regressions provided a significantly better fit to the values than either the pooled single regression or parallel line regressions with common slope and separate intercepts for each animal. The means (with SEM) of the individual regressions were calculated: for abomasal outflow $(\mathrm{ml} / \mathrm{h}), t / 2(\mathrm{~min})$ and abomasal volume $(\mathrm{ml})$ the slopes were $0.327(0.069), 0.0052(0.0036)$ and $0.344(0.050) \mathrm{g} \mathrm{FI} / \mathrm{d}$ respectively.

Using the individual regressions there was no significant correlation between $t / 2$ and the level of food intake although there was a trend towards a slight increase in $t / 2$ with increase in food intake in five of the six sheep. There was a highly significant relation between abomasal outflow and the level of food intake $(P<0.01)$ and between abomasal volume and food intake $(P<0.001)$. 


\section{Relation between food intake and small intestinal transit time}

The transit time of Phenol Red marker through the small intestine varied inversely with the level of food intake in each animal. There was a considerable variation in the transit time between individual animals at each level of food intake, but a similar change in transit time per unit change in food intake in each sheep (Fig. $4 a$ ). The mean (with SE) common slope from these regressions was $-0.0549(0.0057) \mathrm{min} / \mathrm{g}$ FI per $\mathrm{d}$, showing a highly significant relation $(P<0.001)$ between food intake and small intestinal transit time. When allowance was made for between-sheep variation in transit time at a given food intake (see Fig. $4 b)$, there was little scatter of values about the mean regression $(r 0.739)$.

\section{DISCUSSION}

The decrease in the retention time of marker in the GI tract of sheep and other ruminants with increased level of food intake (Blaxter et al. 1956; Shellenberger \& Kesler, 1961; Demarquilly \& Journet, 1967; Leaver et al. 1969; Alwash \& Thomas, 1971; Grovum \& Williams, 1973a, 1977) appears to be mainly due to changes in marker retention in the reticulo-rumen (Blaxter et al. 1956; Grovum \& Williams, 1977) and the large intestine (Coombe \& Kay, 1965; Grovum \& Hecker, 1973), i.e. the compartments with the longest retention times and which contain the greatest volume of digesta. The retention times in the abomasum (Grovum \& Williams, 1973b) and the small intestine (Coombe \& Kay, 1965; Grovum \& Williams, 1973a) are very much shorter than in the hind-gut or reticulo-rumen. Nevertheless, changes in digesta flow and retention times in these compartments are also important for the digestion and absorption of nutrients, especially in animals infected with GI parasites, as discussed elsewhere (Gregory \& Wenham, 1984). For the reasons described earlier the experiments were performed on young rather than adult animals; nevertheless, there was little increase in body-weight during the study. Radiographic examination of the animals before experimentation indicated that both abomasal emptying and small intestinal flow of digesta were normal in all animals, so the slow growth rate presumably relates to the periods of restricted food supply. It seems, therefore, that the results reported here are unlikely to have been greatly influenced by changes in size of the abomasum or small intestine during the course of the study.

In view of the short retention times in the abomasum and small intestine, it is essential to make direct measurements of flow in these compartments rather than rely on compartmental analysis of excretion curves of marker. The authors are unaware of any previous direct measurements of the relation between food intake and abomasal volume and flow other than single estimates of flow per animal at two levels of food intake (Grovum \& Williams, 1973a) and measurement of flow through a duodenal re-entrant cannula at two levels of food intake (Hogan, 1964), where both the cannula and the sampling are likely to alter normal flow (Wenham \& Wyburn, 1980). Direct measurements of intestinal retention times at different levels of food intake have been reported by Coombe \& Kay (1965) but using only three animals at two or three levels of food intake, and by Grovum \& Williams (1973a) with single measurements at two levels of food intake, and these did not take into account the phase of the MMC which alters the rate of digesta flow (Bueno et al. 1975).

The method used in the present study to estimate abomasal volume and flow relies on a good linear relation between $\log \mathrm{Cr}$ concentration and time. This was achieved in seventy-four out of eighty-eight experiments. The reasons for non-linearity in the remaining fourteen experiments which were discarded could not always be determined, but in eight experiments it appeared to be due to the occurrence of duodenal RSA during the period 
of sampling. The $t / 2$ values by this method are within the range calculated from Hyden (1961) and observed by Grovum \& Williams (1973 b) of approximately 17-42 min.

The liquid marker used gives a measure of the fluid outflow from the abomasum. Since fluid represents some $94-97 \%$ of total abomasal outflow (Faichney \& Griffiths, 1978) the flow measured provides a close approximation to the total emptying rate. When CrEDTA is administered to the rumen of sheep about $3 \%$ is excreted in the urine (Binnerts et al. 1968) although the site of absorption is not known. Absorption from the abomasum is therefore unlikely to affect the results of the present experiment significantly. The values recorded for abomasal outflow represent a slight overestimate of the mean hourly flow per $d$, since they do not take into account the brief period (5-10 $\mathrm{min}$ ) of abomasal inhibition following a duodenal RSA (Ruckebusch \& Bueno, 1977; Wenham \& Wyburn, 1980), as illustrated in Fig. 1. Previous studies have shown a wide variation in the level of abomasal outflow and, indeed, of flow from day-to-day and during the same day in single individuals, e.g. $13300-24000 \mathrm{ml} / \mathrm{d}$ at $1700 \mathrm{~g}$ daily food intake (Hogan, 1964) and $8200-16500 \mathrm{ml} / \mathrm{d}$ at $1100 \mathrm{~g}$ daily food intake (Poncet et al. 1977). Taking into account the period of abomasal inhibition with each MMC (mean (with SE) 18 (2)/24 h) the present values fall within these ranges, and are similar to the values reported for hourly fed sheep of $8165 \mathrm{ml} / \mathrm{d}$ at $400 \mathrm{~g}$ intake, and $21700 \mathrm{ml} / \mathrm{d}$ at $1200 \mathrm{~g}$ intake (Grovum \& Williams, 1973a). It has been reported that sheep fed three times daily have approximately double the abomasal outflow of sheep fed the same quantity once daily (Harrison \& Hill, 1962). In the present study, feeding by continuous belt-feeder could have led to the high rates of flow observed. It may also have helped to reduce the variability of the results, although some variability remained within individual sheep at the same level of food intake. By plotting the regressions from about twelve measurements in each sheep this problem was partly overcome but significant differences were observed between the individual animals. However, in each case it was evident that there was quite close correlation between the regressions of five of the six sheep, i.e. for all except sheep no. 6176 for abomasal volume (Fig. $3 a$ ) and flow (Fig. $3 c$ ) and except for sheep no. 5765 for $t / 2$ (Fig. $3 b$ ). It was therefore concluded that the mean of the individual regressions for each index gave a true reflection of the response of this group of animals rather than the regressions from the pooled values. There was a linear relation between the level of food intake and both abomasal volume and abomasal outflow but there was no consistent relation with the $t / 2$ of marker dilution even though there was a trend towards a slight increase in $t / 2$ with increase in food intake (seen in five of the six animals).

Reducing the level of food intake to about $30 \%$ of the voluntary intake had no effect on the frequency of the duodenal MMC while causing a slight, non-significant decrease in frequency of the jejunal MMC, and a decrease in frequency of duodenal rushes and of the period of ISA. Evidently even more severe alterations of food intake are necessary before the normal MMC frequency is disturbed, such as by complete starvation or with overfeeding of concentrates (Bueno, 1977), although the period and intensity of ISA apparently depends on the amount of digesta flowing from the abomasum.

The transit time of marker through the small intestine was inversely related to the level of food intake. The transit times observed correspond with the reported mean retention time in the small intestine of 1-2 h (Hyden, 1961) 2.3-4.5 h (Coombe \& Kay, 1965) and 91 and $136 \mathrm{~min}$ at 400 and $1200 \mathrm{~g} / \mathrm{d}$ intake respectively (Grovum \& Williams, $1973 \mathrm{a}$ ). Using the method described there was a very good reproducibility of transit time at a given food intake in any one sheep, but considerable variation between individuals. However, each animal showed a similar change in transit time with change in food intake (Fig. $4 a$ ) and by allowing for this individual variation it could be seen that there was a very close relation between food intake and intestinal transit time (Fig. $4 b$ ). Thus, once the transit time in an individual fed at about normal voluntary intake has been established, it should be possible 
to estimate accurately the transit time at different levels of food intake using the mean regression calculated here for animals under the same experimental conditions.

The authors thank Dr F. White and Mr C. A. Simpson for their assistance in the surgical preparation of the animals, Mr I. Robb and Mr R. Middleton for preparing the figures and Dr R. N. B. Kay for his review of the manuscript.

\section{REFERENCES}

Alwash, A. H. \& Thomas, P. C. (1971). Journal of the Science of Food and Agriculture 22, 611-615.

Barreiro, M. A., McKenna, R. D. \& Beck, I. T. (1968). American Journal of Digestive Diseases 13, $222-233$.

Binnerts, W. T., van't Klooster, A. T. \& Frens, A. M. (1968). Veterinary Record 82, 47.

Blaxter, K. L., Graham, N. McC. \& Wainman, F. W. (1956). British Journal of Nutrition 10, 69-91.

Bueno, L. (1977). Comptes Rendus des Séances de la Société de Biologie 171, 959-964.

Bueno, L., Fioramonti, J. \& Ruckebusch, Y. (1975). Journal of Physiology 249, 69-85.

Coombe, J. B. \& Kay, R. N. B. (1965). British Journal of Nutrition 19, 325-338.

Demarquilly, C. \& Journet, M. (1967). Annales de Zootechnie 16, 123-150.

Downes, A. M. \& McDonald, I. W. (1964). British Journal of Nutrition 18, 153-162.

Faichney, G. J. \& Griffiths, D. A. (1978). British Journal of Nutrition 40, 71-82.

Gregory, P. C. (1982). Journal of Physiology 328, 431-447.

Gregory, P. C. \& Wenham, G. (1984). Gut. 25, A1321-A1322.

Grivel, M. L. \& Ruckebusch, Y. (1972). Journal of Physiology 227, 611-625.

Grovum, W. L. \& Hecker, J. F. (1973). British Journal of Nutrition 30, 221-230.

Grovum, W. L. \& Williams, V. J. (1973a). British Journal of Nutrition 29, 13-21.

Grovum, W. L. \& Williams, V. J. (1973 b). British Journal of Nutrition 30, 231-240.

Grovum, W. L. \& Williams, V. J. (1977). British Journal of Nutrition 38, 425-436.

Harrison, F. A. \& Hill, K. J. (1962). Journal of Physiology 162, 225-243.

Hogan, J. P. (1964). Australian Journal of Agricultural Research 15, 384-396.

Hyden, S. (1961). In Digestive Physiology and Nutrition of the Ruminant, p. 35 [D. Lewis, editor]. London: Butterworths.

Leaver, J. D., Campling, R. C. \& Holmes, W. (1969). Animal Production 11, 11-18.

Poncet, C., Dimova, E., Leveille, M. \& Dardillat, C. (1977). Annales de Biologie Animale Biochimie Biophysique 17, $515-522$.

Ruckebusch, Y. \& Bueno, L. (1977). American Journal of Physiology 233, E483-E487.

Shellenberger, P. R. \& Kesler, E. M. (1961). Journal of Animal Science 20, 416-419.

Wainman, F. W., Smith, J. S. \& Dewey, P. J. S. (1975). Journal of Agricultural Science, Cambridge 84, $109-111$.

Warner, A. C. I. \& Stacy, B. D. (1968). British Journal of Nutrition 22, 369-387.

Wenham, G. \& Wyburn, R. S. (1980). Journal of Agricultural Science, Cambridge 95, 539-546. 